\title{
Budding yeast centromere composition and assembly as revealed by in vivo cross-linking
}

\author{
Pamela B. Meluh ${ }^{1}$ and Douglas Koshland \\ Howard Hughes Medical Institute, Carnegie Institution of Washington, Department of Embryology, \\ Baltimore, Maryland 21210 USA
}

\begin{abstract}
The centromere-kinetochore complex is a specialized chromatin structure that mediates bipolar attachment of replicated chromosomes to the mitotic spindle, thereby ensuring proper sister chromatid separation during anaphase. The manner in which this important multimeric structure is specified and assembled within chromatin is unknown. Using in vivo cross-linking followed by immunoprecipitation, we show that the Mif2 protein of the budding yeast Saccharomyces cerevisiae, previously implicated in centromere function by genetic criteria, resides specifically at centromeric loci in vivo. This provides definitive evidence for structural conservation between yeast and mammalian centromeres, as Mif2p shares homology with CENP-C, a mammalian centromere protein. Ndc10p and Cbflp, previously implicated in centromere function by genetic and in vitro biochemical assays, were also found to interact with centromeric DNA in vivo. By examining Mif2p, Ndc10p, and Cbflp association with centromeric DNA derivatives, we demonstrate the existence of centromeric subcomplexes that may correspond to assembly intermediates. Based on these observations, we provide a simple model for centromere assembly. Finally, given the sensitivity of this technique, its application to other sequence-specific protein-DNA complexes within the cell, such as origins of replication and enhancer-promoter regions, could be of significant value.
\end{abstract}

[Key Words: MIF2; CEN P-C; centromere; kinetochore; chromatin immunoprecipitation; CSE4]

Received September 5, 1997; revised version accepted October 23, 1997.

The centromere-kinetochore complex (hereafter centromere or (KC) is a highly specialized chromatin-based organelle that mediates chromosome attachment to and movement upon the mitotic spindle (Brinkley et al. 1992; Pluta et al . 1995). As mitosis proceeds, the centromeres of sister chromatids ultimately interact with microtubules (MTs) from opposite spindle poles, thereby ensuring that each daughter cell will receive a precise complement of chromosomes. The fidelity of chromosome transmission is enhanced not only by the geometry of stable centromere-MT interactions but also by the action of at least one centromere-based mitotic checkpoint control system that monitors those interactions and delays the onset of anaphase until stable bipolar attachment is achieved (Gorbsky 1995; Rudner and Murray 1996). Thus, centromeres play both important structural and regulatory roles in ensuring faithful chromosome segregation during mitosis. To enact these roles, centromeres must contain many proteins including MT binding proteins and motors, cohesion factors, checkpoint proteins, and possibly specific architectural and

${ }^{1}$ Corresponding author.

E-MAIL meluh@mail1.ciwemb.edu; FAX (410) 243-6311. heterochromatin proteins. These proteins must be assembled together at a specific site on the chromosome and function in an integrated fashion with respect to one another and to the cell cycle.

The CKC of mammalian cells has been defined cytologically as a trilaminar disc-shaped structure si tuated at the primary constriction of metaphase chromosomes (Brinkley et al. 1992; Pluta et al. 1995). These structures typical ly engage 15-25 M Ts and encompass up to several megabase pairs of DNA. Their size, combined with the fact that centromeric regions consist largely of heterochromatic blocks of repetitive satellite DNAs, has made it difficult to define functional centromeric DNA sequences in higher eukaryotes. On the other hand, several conserved protein constituents of mammalian centromeric heterochromatin have been identified. CEN P-A (17 kD) contains a carboxy-terminal histone-fold domain similar to that of histone $\mathrm{H} 3$ and may define a class of centromere-specific nucleosomes (Sullivan et al. 1994). CEN P-B (80 kD) is a sequence-specific DN A-binding protein that localizes to the heterochromatic interior of the centromere (Cooke et al. 1990). CEN P-B binds to a subset of the al phoid satellite sequences that comprise human centromeric DN A (M asumoto et al . 1989). CEN P-C $(140 \mathrm{kD})$ is a novel, basic protein that localizes to the 
inner plate of the CKC, a site corresponding to the outermost regi on of the CKC in which DNA can be detected (Saitoh et al. 1992).

Although CENP-A and CENP-B may be involved in packaging the centromeric DNA, their contribution to centromere function is unclear. However, several observations suggest that CEN P-C is an essential component of a functional human centromere. For example, nuclear microinjection of CENP-C-specific antibodies profoundly delays mitosis and causes abnormalities in CKC ultrastructure (Tomkiel et al. 1994). Importantly, these effects correlate with a specific decrease in centromeric CENP-C staining. Conversely, the presence of CENP-C strictly correlates with the ability of a given centromere to support chromosome segregation. Based on cytogenetic analyses of mitotically stable, dicentric or neocentric human chromosomes, only functionally active centromeres contain CEN P-C (Earnshaw et al. 1989; Sullivan and Schwartz 1995; du Sart et al. 1997). In contrast, CENP-B and/or the alphoid satellite DNA it recognizes may or may not be found at active centromeres and can also be found at inactive centromeres. Thus, it has been suggested that CEN P-C is an important architectural component of the active mammalian centromere.

The CKC of the budding yeast Saccharomyces cerevisiae is functionally similar to those of higher eukaryotes, harboring activities for MT binding (Kingsbury and Koshland 1991), potential anaphase A movement (Guacci et al . 1997), and activation of the mitotic checkpoint (Pangilinan and Spencer 1996). However, the centromere of budding yeast appears to be a much simpler organelle than its mammalian counterpart, engaging only a single MT (Winey et al. 1995). Yeast centromeric ultrastructure has been impossible to visual ize by electron microscopy, perhaps because of its small size $(<200$ bp).

The centromeric DNA (CEN DNA) of S. cerevisiae is one of the best characterized DNA segregation elements, largely owing to the development of sensitive genetic assays for centromere function in this organism (Hegemann and Fleig 1993; Hyman and Sorger 1995). The minimal functional centromere ( 120 bp) is comprised of three conserved centromere DNA elements (CDEs). The central element, CDEII, consists of al ternating stretches of $A$ and $T$ residues and is flanked by two highly conserved palindromic motifs, CDEl (8 bp) and CDEIII (25 bp). Of these, CDEIII and at least part of CDEII are essential for centromere function. In vivo, a unique nuclease-resistant chromatin structure encompassing 200 bp is associated with CEN DNA and presumably corresponds to the yeast CKC (Bloom and Carbon 1982). Five genes that encode yeast centromere proteins have been identified by a combination of genetic and biochemical approaches. Four of these-NDC10/ CBF2 (Goh and Kilmartin 1993; Jiang et al. 1993), CBF3B/CEP3 (Lechner 1994; Strunnikov et al. 1995), CTF13 (Doheny et al. 1993), and SKP1 (Connelly and Hieter 1996; Stemmann and Lechner 1996)-are essential for viability and encode components of a multisub- unit complex (CBF3) that binds to CDEIII DNA in vitro (Lechner and Carbon 1991). In addition, CBF1/CEP1/ CPF1 encodes a nonessential basic helix-loop-helix protein that binds to CDEI DNA in vitro (Baker and Masison 1990; Cai and Davis 1990; Mellor et al. 1990). Mutations in these five genes impair chromosome segregation, thereby further implicating them as centromere protein genes. However, occupation of CEN DNA in vivo by any of the corresponding proteins has not been demonstrated. Moreover, that none of these proteins shares homology with CEN P-A, CENP-B, or CEN P-C suggested that yeast and mammalian centromeres have different architectures and distinct mechanisms of assembly.

An indication that this hypothesis is incorrect came with the identification and characterization of the yeast MIF2 gene and protein (Mif2p). By several criteria, MIF2 may also encode a centromere component. MIF2 is essential, and mutations in the gene confer phenotypes consistent with a centromere defect. These include chromosome mis-segregation, disruption of mitotic spindle integrity, stabilization of dicentric minichromosomes, and synergistic increases in chromosome loss or synthetic lethality when combined with mutations in various cis- and trans-acting components of the centromere (Brown et al. 1993; Meluh and Koshland 1995). Interestingly, two regions of $\mathrm{Mif2p}$ essential for its function share homology with the two most highly conserved regions of the mammalian centromere protein CEN P-C (Brown 1995; Meluh and Koshland 1995). With the completion of the Yeast Genome Project, it is now clear that $M$ if2 $p$ represents the best candidate for a yeast CENP-C homolog. In addition, $M$ if $2 p$ has two features that suggest it interacts with DNA: an "A-T hook" motif common to several chromatin proteins that bind AT-rich DNA [e.g., mammalian HMG-I(Y) proteins], and an acidic domain (Brown et al. 1993). Taken together, these genetic and structural features suggest that $\mathrm{M}$ if2p interacts with both $\mathrm{Cbf} 1 \mathrm{p}$ and components of CBF3, possibly while bound to the central AT-rich CDEII el ement. Thus, like CEN P-C, M if2p may serve as an architectural component of a higher order centromere complex.

Although these observations strongly implicated Mif2 $p$ as a yeast centromere protein, they did not exclude other interpretations, especially because Mif2p was not among the handful of CEN DNA-binding proteins previously identified and because the similarity between M if2p and CEN P-C is quite limited. Conceivably, the effects of mif2 mutations on centromere function could reflect an indirect effect on the expression of CBF3 components. In light of the potential implications of structural conservation within the centromeres of diverse organisms, it was imperative to demonstrate that Mif2p directly interacts with the centromere. Here we anal yze M if2p function by indirect immunofluorescence and by an in vivo cross-linking and immunoprecipitation strategy. We show that M if2p specifically interacts with CEN DNA in vivo in a pattern that correlates with centromere function. 


\section{Results}

\section{Mif2p is a nuclear protein}

To determine the distribution of Mif2p in cells, antisera specific for the carboxyl terminus of M if2p (amino acids 364-549), as well as a functional epitope-tagged allele of MIF2, MIF2-HA (hemagglutinin), were generated. Both crude sera recognize a 94-kD protein in yeast whole cell extracts (Fig. 1A). This apparent molecular mass is significantly greater than that predicted from the MIF2 coding sequence (maximally 62.5 kD; Brown et al. 1993).
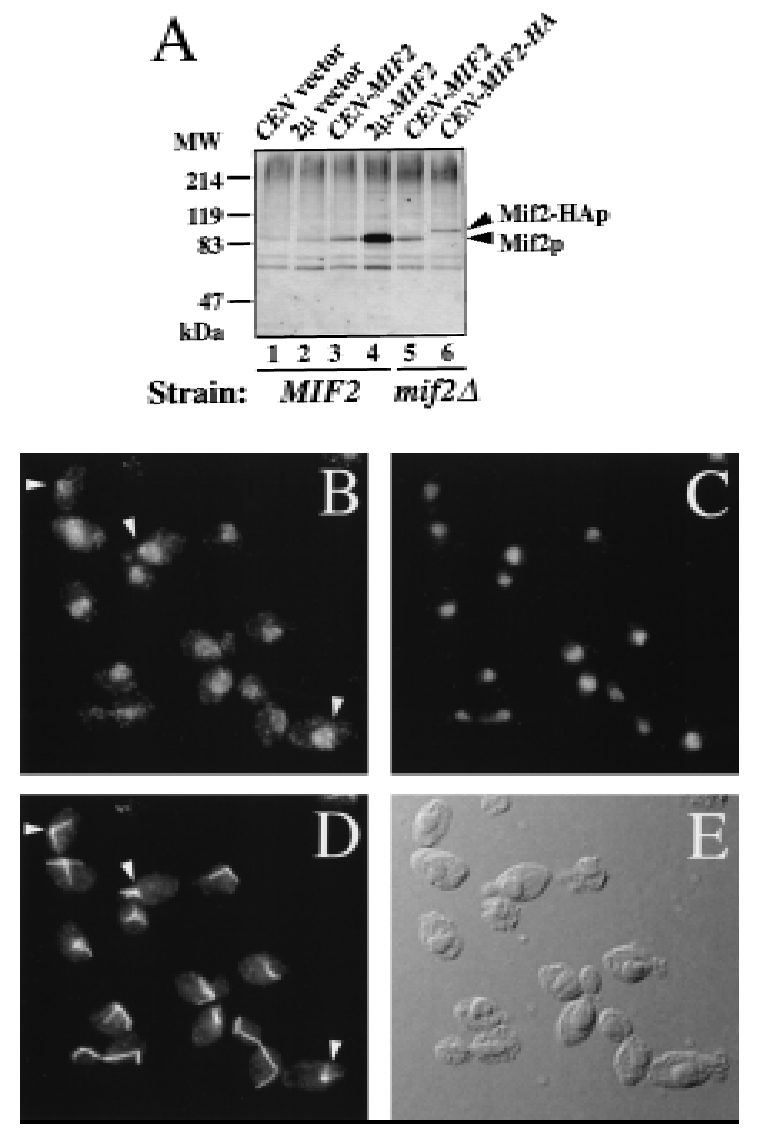

Figure 1. Characterization of Mif2p by Western analysis and indirect immunofluorescence. (A) Western analysis of Mif2p in whole cell extracts from logarithmically growing yeast strains $\left(30^{\circ} \mathrm{C}\right)$. M if2 $p$ was detected using anti-M if2p antiserum and che miluminescence. Mif2p migrates as at 94 kD; Mif2-HAp migrates at $\sim 102$ kD. (Lane 1) Wild-type strain 5371-10-2 with pRS316, CEN 6 U RA 3 vector (Sikorski and Hieter 1989); (lane 2) 5371-10-2 [pRS202], 2 $\mu$ U RA 3 vector; (lane 3) 5371-10-2 [pPM 4], pRS316-MIF2; (lane 4) 5371-10-2 [pPM 44], pRS202-MIF2; (lane 5) PM 1202-7B, mif2::HIS3 [pPM4]; (lane 6) PM 1203-1C, mif2::HIS3 [pPM 102], pRS316-MIF2-HA. Molecular masses of protein standards are indicated (MW). (B-E) Localization of Mif2p in wild-type diploid cells (BP5050; $30^{\circ} \mathrm{C}$ ) by indirect immunofluorescence. (B) Mif2p staining as visualized by affinity-purified anti-Mif2p; (C) Total DNA as detected by DAPI staining; (D) MTs as visualized by anti- $\alpha$-tubulin; (E) DIC image of field. Brighter foci of Mif2p staining are indicated by arrowheads.
However, the detected protein is Mif2p, as its steadystate level increases in strains that overexpress Mif2p and because its relative mobility decreases in extracts prepared from MIF2-HA strains. The aberrant migration may be due to the presence of a highly acidic region in Mif2p (amino acids 178-263), as has been observed for other proteins that contain acidic domains, notably the yeast CDEl-binding protein Cbflp (Baker and Masison 1990).

One of the sera was affinity purified and used for indirect immunofluorescence of asynchronously grown wild-type yeast diploid cells. Consistent with the hypothesis that Mif2p is a centromere protein, a dim nuclear staining pattern was observed in cells at all stages of the cell cycle (Fig. 1B). In addition, in most unbudded and small budded cells a brighter focus of staining in the vicinity of the spindle pole body could be seen (arrowheads, Fig. 1B). Brighter staining foci were not evident in cells at later stages of the cell cycle. In cells that overexpress Mif2p or M if2-HAp, general and bright nuclear staining was observed (data not shown). Thus, Mif2p is a nuclear protein. In addition, the pattern of spindle pole body proximal staining early in the cell cycle is reminiscent of the position of the centromeric DNA at this time as revealed by fluorescence in situ hybridization (Guacci et al. 1997). Lack of focal staining at later times may reflect masking of $M$ if $2 p$ upon assembly of other centromere proteins (see below).

\section{Mif2p interacts with CEN DNA in vivo}

Although punctate nuclear staining for Mif2p is consistent with centromere association, such localization does not rigorously distingui sh whether M if2p acts at the centromere, at the spindle pole body, or within the spindle. To further implicate Mif2p as a centromere-associated protein, we first tried a gel mobility shift assay similar to that used to demonstrate in vitro CEN DNA binding by Cbflp and the CBF3 complex (Doheny et al. 1993; Sorger et al. 1994, 1995). However, our attempts were unsuccessful (data not shown). Conceivably, formation or resolution of higher order structures containing M if2p is precluded under conditions where Cbf1p- and CBF3-CEN DNA subcomplexes are detected. CBF3 reconstituted from highly purified components and CBF3 affinity-purified from cell extracts exhibit identical CEN-binding properties (Stemmann and Lechner 1996). Therefore, as an alternative approach to study potential Mif2p-CEN DNA interactions, we used the technique of formal dehyde fixation followed by chromatin immunoprecipitation (Dedon et al. 1991; Braunstein et al. 1993; Orlando and Paro 1993; Hecht et al. 1996; Orlando et al. 1997). The choice of formal dehyde, which creates heat-reversible cross-links between proteins, as well as between proteins and nucleic acid, rendered assumptions about the primary nature of any Mif2p-CEN DN A interaction unnecessary.

To test whether Mif2p interacts with CEN DNA in vivo, wild-type yeast cells in mid-logarithmic phase were first fixed in situ with $1 \%$ formaldehyde. A soni- 
cated chromatin solution prepared from the fixed cells was then subjected to immunoprecipitation with antiMif2p antisera. The presence of various DNA sequences in the immunoprecipitates was assessed by slot bl ot hybridization. Several CEN DNA sequences tested (i.e., CEN 3, CEN 16, and CEN 1) were enriched in M if2p immunoprecipitates as compared to a mock-treated control (Fig. 2A; data not shown). The enrichment was specific for $M$ if2p, as it was abrogated by the addition of recombinant $M$ if2 antigen to the immunoprecipitation reaction (Figs. 2A and 3B). CEN DNA sequences were similarly enriched when affinity-purified M if2p antibody was used (Fig. 2A) or when a well-characterized anti-HA antibody was used with chromatin prepared from the MIF2-HA strain (Fig. 2B). Finally, for a given CEN DNA Iocus, the fraction of total material present in M if2p immunoprecipitates increased with fixation time (Fig. 2C). These data indicate that $\mathrm{M}$ if2 $\mathrm{p}$ interacts, either directly or indirectly, with CEN DNA in vivo. Importantly, several other genomic loci, including regions with high AT content (Figs. 2A and 4F) were not enriched in Mif2p immunopreci pitates, suggesting that M if2 $p$ interacts exclusively with centromeric regions. Thus, as predicted by its numerous genetic interactions with centromere components, $M$ if $2 p$ is a centromere-associated protein in vivo.
CDEIII is both necessary and sufficient for the Mif2p-CEN DNA interaction

To further characterize the Mif2p-CEN DNA interaction, we tested whether $M$ if $2 p$ interacts with segregation-incompetent derivatives of CEN 3 that were integrated at the URA3 locus (Fig. 3A). Southern blot (Fig. 3B) or PCR (Fig. 4) analysis of DNA that coimmunoprecipitated with M if2 $p$ allowed the authentic CEN 3 locus to be distinguished from each ectopic locus (Fig. 3B, asterisks). A single-base-pair change in the central conserved cytidine residue of CDEIII (cen3-BCT2; M cGrew et al. 1986) disrupted the M if2p-CEN DN A interaction (Figs. 3B, left, and 4B), indicating that intact CDEIII is necessary. Consistent with this, Mif2p failed to interact with a wild-type CEN3-CDEI +II subfragment (Figs. 3B, middle, and 4C). Mif2p is, nonetheless, capable of interacting with CEN DNA within the context of the URA3 locus, as a wild-type CEN3-CDEIII subfragment was enriched in $\mathrm{M}$ if2p immunoprecipitates (Figs. 3B, right, and 4D). Thus, CDEIII is both necessary and sufficient for the Mif2p-CEN DNA interaction in vivo. Moreover, as the cen3-BCT2 (or related) mutation abolishes all known in vivo and in vitro aspects of centromere function (M CGrew et al. 1986; N g and Carbon 1987; Saunders et al. 1988; Kingsbury and Koshland 1991; Lechner and Car-
Figure 2. Coimmunoprecipitation of CEN DNA with Mif2p. (A) Formal dehyde cross-linked chromatin (2 hr fixation) prepared from wild-type strain 5371-10-2 was immunopreci pitated with anti-M if2p antibodies in the absence or presence of recombinant 6 -His-Mif2 fusion protein. Some reactions were prepared in duplicate. Total input material and coimmunoprecipitated DNA were analyzed by slot blot hybridization with the indicated probes. The percent of total input material for a given locus present in an immunoprecipitate is indicated to the right of each panel. The variable low levels of material detected by the TUB2 and total genomic DN A probes probably reflect contaminating RN A, although noncentromeric chromatin may exhibit some insolubility as compared to centromeric chromatin. (B) Cross-linked chromatin (2 hr fixation) prepared from mif2::HIS3 strains expressing either wild-type MIF2 or epitope-tagged MIF2-HA from a centromere-based plasmid was immunoprecipitated with antiMif2p antiserum or anti-HA antibody. Coimmunoprecipitated DNA was analyzed by slot blot hybridization using a CEN3specific probe. (C) Time course of fixation. Cross-linked chromatin prepared from the MIF2-HA strain after various times of fixation was mock-treated (shaded circle) or immunopreci pitated with anti-M if2p antiserum (black square) or anti-HA (black diamond) and analyzed as in B. The percent of total input CEN 3 DN A that coimmunoprecipitated with Mif2-HAp was plotted. Identical results were obtained in B and C using a CEN 16 probe (data not shown). That CEN DN A recovery was consistently greater in immunoprecipitates prepared with authentic M if2p antibodies as compared to anti-HA presumably reflects the polyclonal nature of these sera.

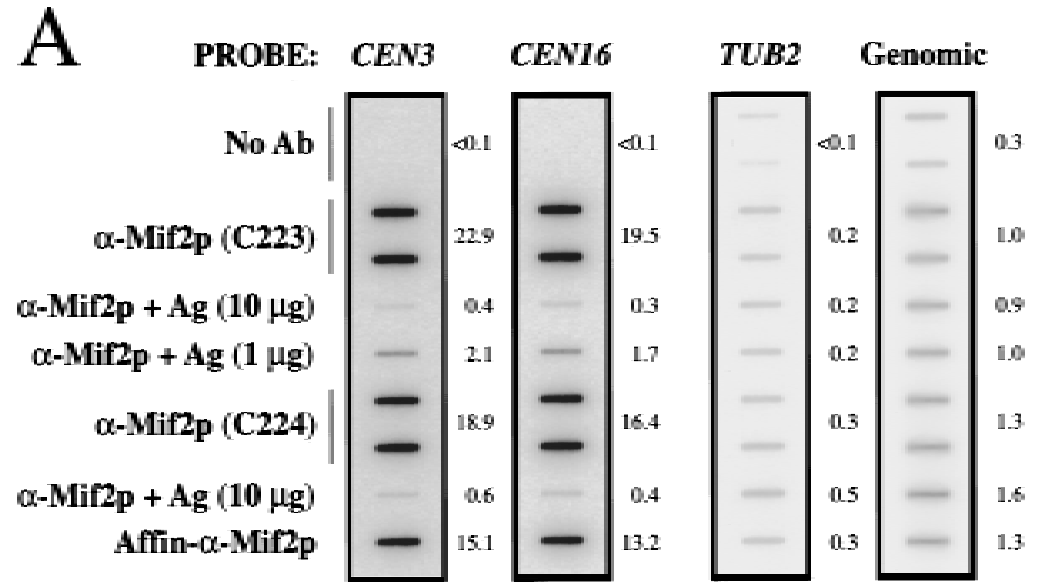

B
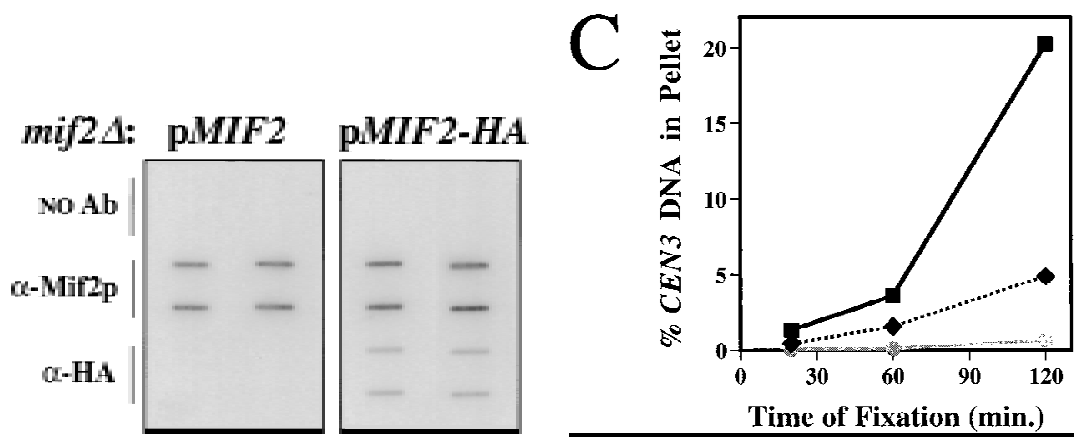

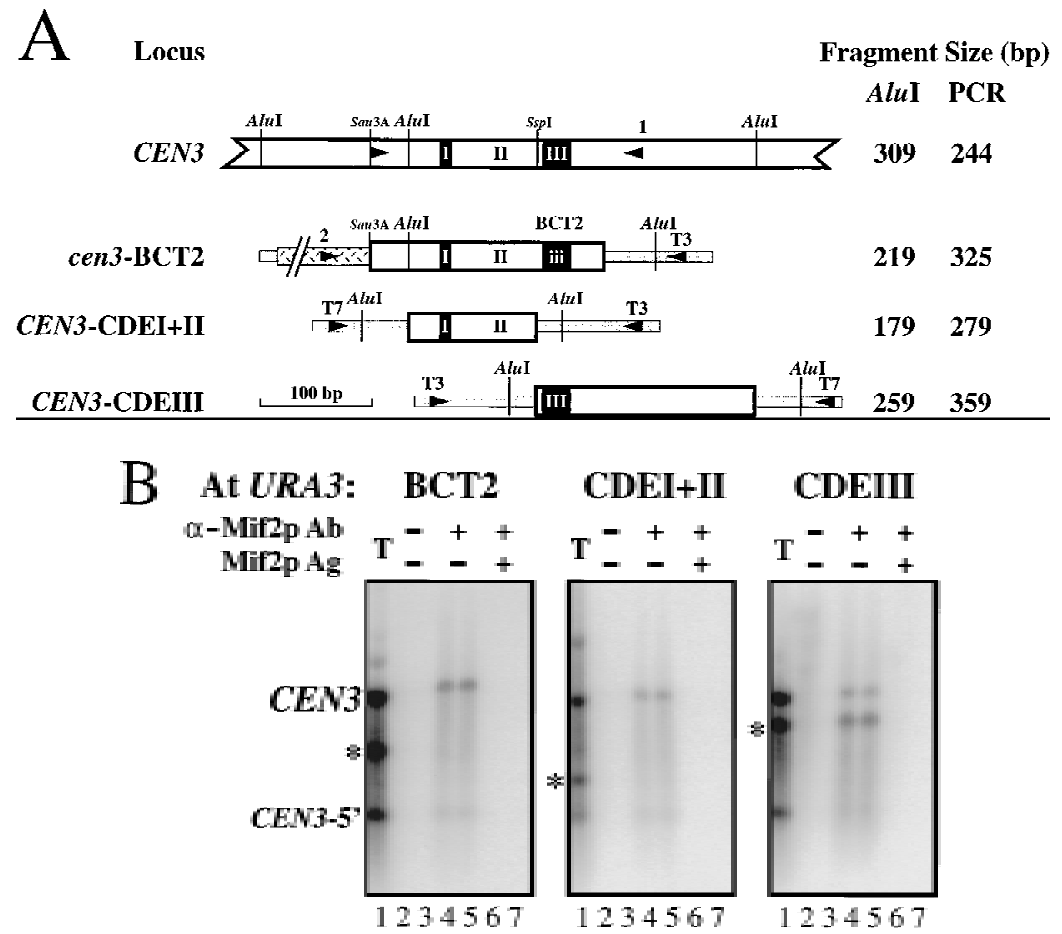

Figure 3. Interaction of Mif2p with segregationincompetent derivatives of CEN3. (A) Schematic of the CEN 3 genomic locus and three segregationincompetent CEN 3 derivatives that were individually integrated at the URA3 locus of wildtype yeast strain MS10. The predicted sizes of CEN3-containing Alul restriction fragments or PCR products are listed. Shading indicates the pBluescript polylinker present in the integrating vector pRS306 (Sikorski and Hieter 1989). Hatching indicates pBR322 sequences present in the cen3-BCT2 construct. Arrowheads designate positions of PCR primers (see $\mathrm{Ma}$ terials and Methods). (B) Crosslinked chromatin (1 hr fixation) prepared from the URA3:: cen3-BCT2, URA 3::CEN 3-CDEI HI, and URA3:: CEN3-CDEIII strains was mock treated (lanes 2,3 ) or immunoprecipitated with anti-M if2p antiserum (C223) in the absence (lanes 4,5 ) or presence of recombinant Mif2 protein (lanes 6,7). Reactions were prepared in duplicate. Total input material (T) and coimmunoprecipitated DNA were digested with Alul and analyzed by Southern blot hybridization with a CEN3-specific probe. Coimmunopreci pitated DN As were loaded in sixfold excess rel ative to the total. The asterisk in each panel indicates the position of the Alul fragment diagnostic for the ectopic locus. Background hybridization reflects prior sonication of the chromatin. bon 1991; Schulman and Bloom 1993; Sorger et al. 1994), we concl ude that the interaction of M if2p with wild-type CEN DNA is biologically relevant.

Ndc10p and Cbf1p also interact with CEN DNA in vivo

To validate our conclusions regarding Mif2p and to initiate a dissection of yeast centromere architecture and assembly, we extended in vivo cross-linking analysis to $\mathrm{N} \mathrm{dc10p}$ and Cbf1p, two proteins established previously as centromere components by genetic criteria and various in vitro biochemical assays. $\mathrm{N} d c 10 p$ could be crosslinked to wild-type CEN DN A (Figs. 4A and 5) but not to several noncentromeric loci (Fig. 4E,F). The Ndc10pCEN DNA interaction was abolished by the cen3-BCT2 mutation (Fig. 4B). In addition, the wild-type CEN3CDEIII subfragment (Fig. 4D), but not the complementary CEN 3-CDEI+HI (Fig. 4C) subfragment, was enriched in $\mathrm{Ndc10p}$ immunoprecipitates. Therefore, as with Mif2p, the Ndc10p-CEN DNA interaction occurs through CDEIII and is dependent on the integrity of this element. Thus, $\mathrm{N}$ dc10p is a centromere-associated protein in vivo and its association follows a pattern consistent with the criteria original ly used to isolate the CBF3 complex ( $\mathrm{Ng}$ and Carbon 1987; Lechner and Carbon 1991). By extension, we presume the other CBF3 components-namely, Cbf3Bp, Ctf13p, and Skplp-are also centromere associated in vivo. N onetheless, the observation that both Mif2p and $\mathrm{Ndc10p}$ can interact with isolated CDEIII motifs in vivo demonstrates the existence of centromeric subcomplexes. The occurrence of such subcomplexes is consistent with previous reports that CDEIII, although incapable of mediating accurate chromosome segregation on its own, is not genetically neutral and can act in cis to reduce the copy number of an otherwise high-copy-number episome (Schulman and Bloom 1993).

An epitope-tagged version of Cbf1p (Cbf1-HAp) could also be cross-linked to wild-type CEN DN A (Figs. 4A and 5). Thus, this protein is centromere associated in vivo, as predicted from previous studies. However, no interaction was detected between Cbf1-HAp and any segregation-incompetent CEN3 derivative, even though cen3BCT 2 and CEN3-CDEI HI each contain an intact CDEI octamer. In contrast, purified Cbflp or Cbflp in crude lysates can readi ly bind to $\mathrm{CDEl}$-contai ning fragments in vitro (Baker et al. 1989; Baker and M asi son 1990; Cai and Davis 1990; M ellor et al. 1990; Sorger et al. 1995; Kuras et al. 1997). Thus, the Cbf1p-CEN DNA interaction is independent of CDEIII in vitro but dependent on CDEIII in vivo.

Interactions of Mif2p, Ndc10p, and Cbf1p are limited to the centromeric region

It was of interest to determine the extent to which centromere proteins associate with DNA surrounding the CEN DNA proper. Although centromere function is specified by a 120-bp sequence, it is possible that the 


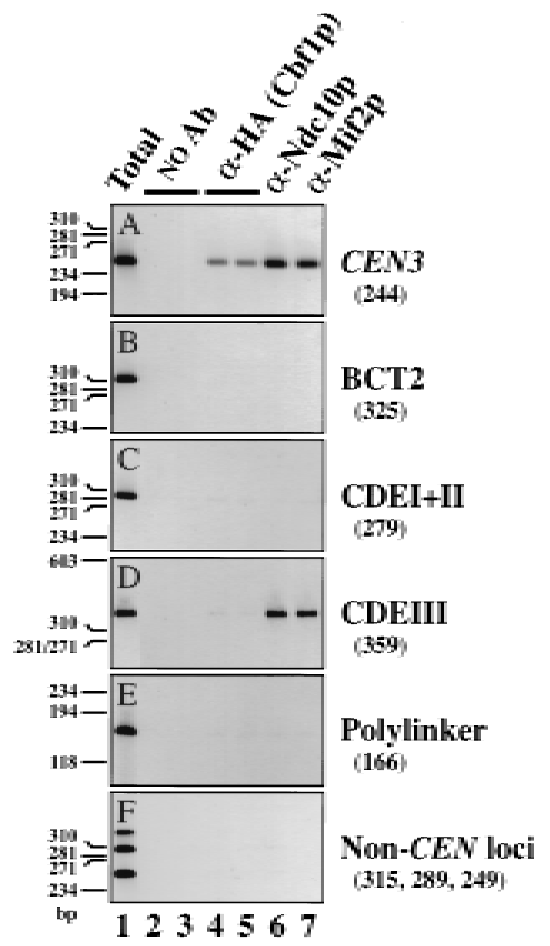

Figure 4. Interaction of centromere proteins Cbf1p and N dc10p with CEN3 DNA. Cross-linked chromatin (2 hr fixation) was prepared from a set of epitope-tagged CBF1-HA strains in which either pRS306 [vector (polylinker)] or segregation-incompetent CEN 3 derivatives (Fig. $3 A$ ) were integrated at the U RA 3 locus. Chromatin was mock-treated (lanes 2,3) or immunoprecipitated with anti-HA [specific for Cbf1-HAp; (lanes 4,5)], an affinity-purified anti-N dc10p antibody (lane 6), or anti-M if2p antiserum (lane 7). Aliquots of total input material $(\approx 3 \mu$ l chromatin solution) and coimmunoprecipitated DNA $(\approx 30 \mu \mathrm{l}$ chromatin solution) were analyzed by PCR with primers specific for the authentic CEN 3 locus (A), the integrated constructs (B-E), or three noncentromeric loci on yeast chromosome III (F) (see $M$ aterials and $M$ ethods for details). Shown are negative images of the ethidium bromide-stained products resolved by PAGE. Size standards are indicated to the left of each panel. Expected sizes of the PCR products are in parentheses. $A$ and $F$ are from the URA3::cen3-BCT2 strain; identical results were obtained for the other three strains (data not shown).

functional centromeric domain extends beyond the CEN DNA in a sequence-independent fashion. For example, nuclease protection studies indicate that CEN3 is flanked by phased nucleosomes (Bloom and Carbon 1982). Conceivably, one or more centromere proteins also interact with these nucleosomes. To explore this possibility, we analyzed DNA that coimmunoprecipitated with Mif2p, Ndc10p, or Cbf1p for the presence of sequences adjacent to the CEN DNA (Fig. 5A). PCR anal ysis of $\sim 2 \mathrm{~kb}$ encompassing the CEN 3 genomic locus reveal ed that only the CEN DNA-containing region was strongly enriched in the immunoprecipitates. If a protein partici pated in interactions beyond the CEN DN A, more than one PCR fragment should have been strongly amplified. Therefore, we conclude that interactions de- tected at CEN 3 are limited to the immediate vicinity of the CEN DNA. Moderate enrichment of the more CENproximal regions presumably reflects the heterogeneous nature of the sonicated chromatin. Similar results were obtained for the CEN 16 locus (Fig. 5B). The simplest interpretation of these data is that Mif2p, Ndc10p, and Cbf1p interact solely with CEN DNA regions and that any hypothetical centromeric domain that extends be yond the CEN DNA is not defined by these proteins.

\section{Discussion}

Mif2p as a centromere protein

Here we show that the $S$. cerevisiae M if2 protein, which shares homology with the mammalian centromere pro-
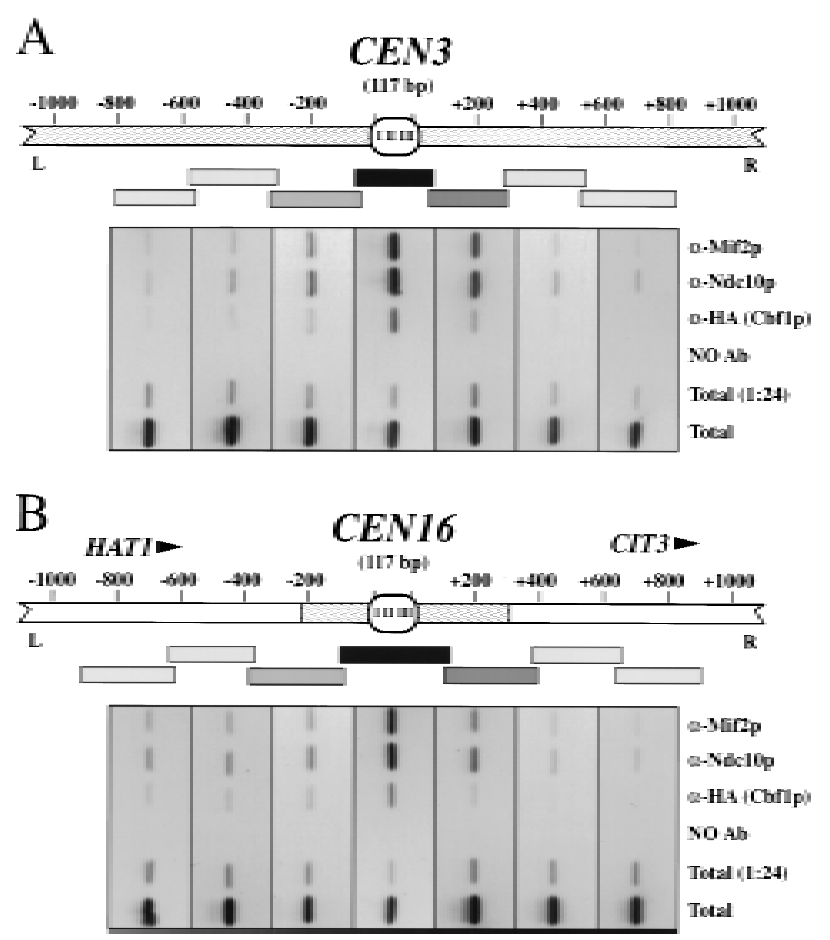

Figure 5. Interactions of $\mathrm{M}$ if $2 p, \mathrm{~N}$ dc10p, and $\mathrm{Cbf} 1 \mathrm{p}$ are limited to the CEN DNA. The CEN3 (A) and CEN 16 (B) chromosomal regions are represented. Stippling corresponds to noncoding DNA; orientation and position of open reading frames near CEN 16 are indicated. Cross-linked chromatin ( $2 \mathrm{hr}$ fixation) prepared from a CBF1-HA strain was immunoprecipitated with anti-M if2p, anti-N dc10p, anti-HA (specific for Cbf1-HAp), or mock treated. Total input material, a 1:24 dilution, thereof, and coimmunoprecipitated DNAs were analyzed by PCR as in Fig. 4 , using primers specific for the indicated series of short, overlapping, CEN-flanking fragments (rectangles). Shading indicates the rel ative enrichment in the immunopreci pitates of DN A corresponding to those intervals and is based on the negative images of ethidium bromide-stained PCR products shown below each schematic. Data shown are for chromatin prepared from a URA 3::cen3-BCT2 strain (A) and a URA3::CEN3-CDEI HI strain (B). 
tein CEN P-C, is a nuclear protein that associates with yeast centromeric DNA in vivo. We demonstrate this association using in vivo formal dehyde cross-linking followed by chromatin immunoprecipitation of CEN DNA fragments with $\mathrm{M}$ if2p-specific antibodies. Importantly, Mif2p had not been implicated in centromere function by in vitro tests. Thus, in vivo cross-linking followed by immunoprecipitation should prove complementary to current in vitro approaches to the analysis of budding yeast centromeres.

The Mif2p-CEN DNA interaction occurs primarily through CDEIII. This result seems inconsistent with previ ous speculation that $M$ if2p interacts with CDEII via its potential HMG-I(Y)-related AT-rich DNA-binding motif (Brown et al. 1993; Meluh and Koshland 1995). Our data do not exclude this possibility but simply imply that any such interaction must be dependent on CDEIII. For example, Mif2p might associate with CDEII by a cooperative assembly process that initiates at CDEIII. Assembly would be limited to the CEN DNA, however, as we did not detect interactions outside the immediate centromeric region. How M if2p interacts with CDEIII in vivo is unclear. The initial interaction could be direct, perhaps through the AT-rich flanks of CDEIII. All 16 CDEIIIs conform to the consensus 5'-tGttTtTG-tTTCCGAAa--aaAa-3'. However, Mif2 $p$ has eluded detection as a CDEIII-binding protein in vitro. Alternatively, Mif2p could interact with CDEIII indirectly through components of the CBF3 complex. In this regard, MIF2 and NDC10 show allele-specific genetic interactions (M eluh and Koshland 1995). Also, we have found that mutations in NDC10 substantially diminish the Mif2p-CEN DNA interaction at the nonpermissive temperature (data not shown). Thus, the presence of M if2p at the centromere might be stabilized by contacts with $\mathrm{Ndc10p}$, as well as with the AT-rich portions of CDEIII and/or CDEII. This model is consistent with our view of the budding yeast centromere as a stereospecific complex (Meluh and Koshland 1995). Finally, a protein capable of binding isolated CDEIII, but that may bind more efficiently to CEN DNA containing both CDEII and CDEIII, has been inferred from in vitro studies of partial ly reassembled yeast CKCs (Sorger et al. 1994). In light of the preceding discussion, Mif2p would be a good candidate for this hypothetical centromere factor.

Subcomplexes and centromere assembly in budding yeast

We also used in vivo cross-linking to confirm the presence of $\mathrm{Ndc10p}$ and $\mathrm{Cbflp}$ on budding yeast centromeres. These two proteins had been regarded al most certainly as centromere proteins by virtue of a large body of genetic and in vitro biochemical data. Analyses of the interactions of $\mathrm{M}$ if $2 \mathrm{p}, \mathrm{N} d \mathrm{c} 10 \mathrm{p}$, and $\mathrm{Cbf1p}$ with segregation-incompetent centromere derivatives produced an unexpected result that may provide insight into centromere assembly in budding yeast. $\mathrm{N}$ amely, we found that in vivo the Cbflp-CEN DNA interaction was dependent on CDEIII, whereas in vitro Cbflp can bind to CDEI independently of other factors (Baker et al . 1989; Kuras et al. 1997). One explanation for the in vivo result might be that the interaction we detect reflects an indirect crosslink through the CBF3 complex rather than a direct cross-link of Cbf1p to CDEI. This interpretation would agree with genetic arguments for physical association of Cbflp and CBF3 in vivo (summarized in Meluh and Koshland 1995).

A more interesting explanation for the requirement of CDEIII in Cbf1p-CEN DNA interaction stems from our identification of M if2p- and N dc10p-containing subcomplexes on isolated CDEIII DNA. The potential for such subcomplexes was anticipated by the ability of isolated CDEIII motifs to act in cis to reduce plasmid copy number (Schulman and Bloom 1993). Conceivably, CDEIII subcomplexes correspond to authentic centromere assembly intermediates. In such a scenario, centromere as-

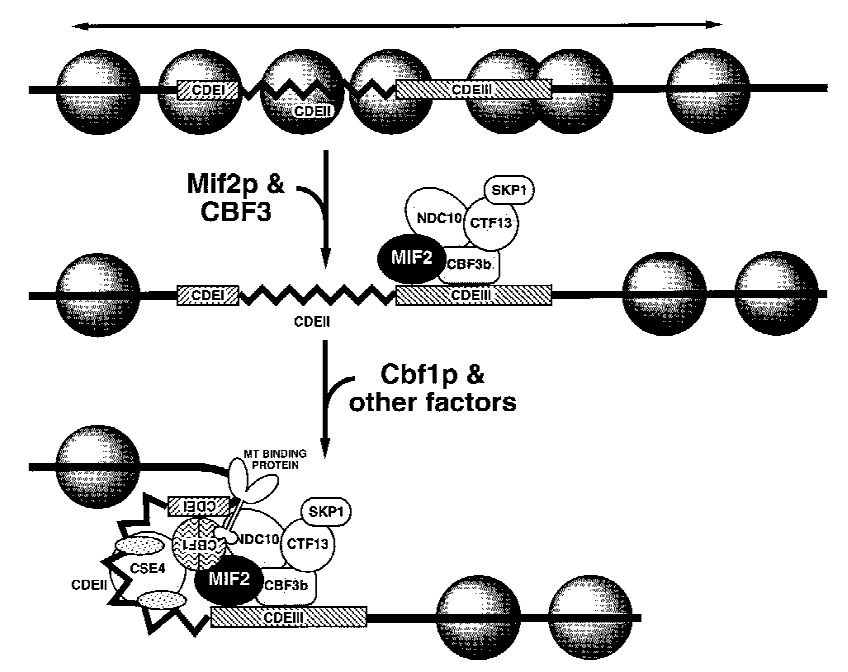

Figure 6. Model for assembly of the budding yeast CKC in vivo. Conserved centromeric DNA elements, CDEI (8 bp) and CDEIII (25 bp), indicated as hatched boxes, flank AT-rich CDEII (78-87 bp). CDEIII is both necessary and sufficient for the interaction of M if2p and N dc10p with CEN DNA in vivo. $\mathrm{N} \mathrm{dc10p}$ is a component of the multiprotein CDEIII-binding complex, CBF3, as are Cbf3Bp, Ctf13p, and Skplp. CDEIII is also necessary, though not sufficient, for interaction of the CDEI-binding protein, Cbf1p, with CEN DNA in vivo. The observed in vivo dependence of the Cbf1p-CEN DNA interaction on CDEIII suggests that centromere assembly initiates with binding of factors at CDEIII (e.g., CBF3 components, indicated in gray, and M if2p), which in turn nucleate further centromere assembly. N ucleosomes are represented by shaded spheres. Potential repressive chromatin that would preclude independent association of some factors (e.g., Cbflp) is indicated by the horizontal arrow. Other factors comprising the mature CKC might include one or more MT-binding proteins (Kingsbury and Koshland 1991; Sorger et al. 1994), CEN P-A-related Cse4p (Stoler et al. 1995), and mitotic checkpoint proteins (Rudner and M urray 1996). Ordered nucleosomal arrays surround the mature CKC in budding yeast (Bloom and Carbon 1982). Genetic evidence for possible looping in the mature centromere is discussed in Meluh and Koshland (1995). For further explanation, see text. 
sembly would initiate with recruitment of the CBF3 complex and possibly Mif2p to CDEIII (Fig. 6). The resultant subcomplex would then serve as the nucleation site around which a fully functional centromere is assembled if CDEI and CDEII are adjacent. The CDEIII subcomplex could facilitate further assembly directly through protein-protein interactions or indirectly by remodeling nearby chromatin to render the CEN DNA accessible to other centromere factors, such as Cbflp. We note that a related model based on in vitro analysis of centromere reassembly has been proposed by Sorger et al. (1994).

This CDEIII nucleation model for yeast centromere assembly is consistent with the genetic preeminence of CDEIII in centromere specification and function, as well as with additional observations from this and other studies. First, mutations in CDEIII that abolish measurable centromere function (e.g., cen3-BCT2) completely disrupt centromeric chromatin structure as visual ized by in vivo footprinting techniques (Saunders et al . 1988). Second, in this study we observed that strains bearing the isolated cen3-CDEIII and associated protein complex do not exhibit a cell cycle delay as judged by FACS and cytological analyses (data not shown). Thus, as would be expected for a normal intermediate in centromere assembly, the CDEIII subcomplex is not itself perceived as aberrant and does not elicit a mitotic checkpoint response. Third, there is some precedent for facilitated binding of Cbflp to DNA. Specifically, studies addressing the role of $\mathrm{Cbf} 1 \mathrm{p}$ in transcriptional activation of sulfur metabolism genes indicate that al though Cbflp can bind cognate recognition sites independently, its in vitro DNA-binding activity is enhanced by association with two other proteins (Kuras et al. 1997). A similar phenomenon might occur at centromeres, as in vitro DNA binding of Cbf1p to various mutant CDEI DNAs does not strictly correl ate with the in vivo centromere function of those derivatives (Wilmen et al. 1994). Finally, the requirement for chromatin remodeling in the assembly of fully functional centromeres as invoked by the model is supported by the dependence of centromere function and/ or structure on histone level s (Saunders et al. 1990), the histone H3-related Cse4 protein (Stoler et al. 1995), and the chromatin factors Spt4p and Spt6p (Basrai et al. 1996).

As presented, our nucleation model for centromere assembly implies that Mif2 $p$ would normally associate with CEN DNA prior to Cbf1p. However, to explain the requirement for $C B F 1$ in a mif2 mutant background, we suggested previously that Cbflp bound at CDEI enhances centromere association or activity of M if2p (MeIuh and Koshland 1995). As shown here, Mif2p can interact with a CEN3-CDEIII construct in which the nearest CDEl-like element is $>1 \mathrm{~kb}$ away. Although we have not yet tested whether mutant Mif2 $p$ interacts with CEN3-CDEIII, preliminary cross-linking experiments indicate that mutant Mif2p can interact with a CDEIdefective centromere. Therefore, $C$ bflp most likely influences the activity, but not the presence of Mif2p at the centromere.
Conservation of structure and function within the centromere

Although centromeres of diverse organisms clearly possess common functional properties, they vary in size and appearance. It has been an open question whether these intricate machines are built from the same or different parts. Prevailing indications are that centromeres differ substantially among organisms at both the DNA and protein level. In contrast, our finding that $M$ if $2 p$ is a centromere protein suggests that centromeres of budding yeast and mammalian cells are structurally as well as functionally conserved.

Although the precise centromeric functions of CEN P-C and M if2 $p$ have not been determined, certain functional parallels between the two proteins exist. CEN P-C is required for normal centromere assembly and may be an architectural component that mediates interactions at the interface between the centromeric heterochromatin and the outer kinetochore plate to which microtubules attach (Saitoh et al. 1992; Tomkiel et al. 1994). Based on genetic data (M el uh and Koshland 1995), as well as the model for centromere assembly developed here, we speculate that Mif2p also serves an architectural role within the centromere complex, perhaps promoting interactions between factors bound at CDEI and CDEIII. The conserved regions may correspond to surfaces that bind other evolutionarily conserved centromere proteins. Formally, these hypothetical factors could be centromeric chromatin factors that recruit CEN P-C or Mif2p, or distal factors (e.g., MT motor or checkpoint proteins) that are themsel ves recruited to the centromere via CEN P-C or Mif2p. Identification of proteins that interact with CEN P-C and/or Mif2p will hel $p$ distinguish between these possibilities.

We believe that additional examples of structural conservation within the centromere will emerge. In budding yeast, aside from $\mathrm{M}$ if2 $\mathrm{p}$, the best candidate to date for a conserved centromere protein is C se4p. Cse4p was ori ginally identified in a genetic screen for chromosome loss mutants and contains a carboxy-terminal histone H3fold domain similar to that of CENP-A (Stoler et al. 1995). These investigators speculated that like CEN P-A, Cse4p is part of a centromere-specific nucleosome. This notion was strengthened by the isolation of CSE4 as a high-copy suppressor of a histone $\mathrm{H} 4$ allele that affects chromosome stability and progression through mitosis (Smith et al. 1996). Using our cross-linking assay, we have recently found that Cse4p associates with CEN DNA in vivo (P.B. Meluh, P. Yang, L. Glowczeski, D. Koshland, and M.M. Smith, in prep.), strongly supporting the idea that aspects of centromere structure are conserved even at the most intimate level of chromatin organization.

Thus, the first definitive examples of conserved centromere proteins in yeast-Mif2p and Cse4p-correspond to presumed constituents of mammalian centromeric heterochromatin-CEN P-C and CEN P-A, respectively. This raises the possibility that structural properties inherent to the chromatin itself can contrib- 
ute to centromere function, perhaps by providing a unique scaffold for centromere protein assembly or by providing insulation against the negative effects of transcription and/or recombination. An important implication of the observed structural conservation is that paradigms developed in budding yeast will also pertain to mammalian centromeres. Certainly, our findings substantiate the view that the mammalian CKC consists of tandemly repeated MT-binding units similar to the single MT-binding unit represented by the budding yeast centromere (Fitzgerald-Hayes et al. 1982; Zinkowski et al. 1991). Also, the concept of a centromere nucleation complex derived from our observation of CDEIII subcomplexes in vivo may be insightful for thinking about mammalian centromere assembly. Studies suggest that mammalian centromeres assemble on blocks of repetitive DNA at the centromere proper but not on homologous bl ocks at centromere-distal loci (Grady et al. 1992; for review, see Brinkley et al. 1992; Tyler-Smith and Willard 1993; Pluta et al. 1995). One explanation for these observations is that a CDEIII-like subcomplex at the centromere directs assembly of a mature CKC on the surrounding repetitive DNA and is missing at centromere-distal loci. Thus, al though repetitive sequences tend to occur at the centromeres of higher eukaryotes, one cannot rule out the existence of relatively short DN A motifs that would specify a functional centromere.

\section{Conclusion}

In summary, we have used cross-linking foll owed by immunoprecipitation to initiate an in vivo analysis of centromere structure and assembly in budding yeast. Prior to this work, in vivo analysis of yeast centromeric chromatin relied upon nuclease and chemical sensitivity assays, which cannot distinguish direct and indirect effects. Our method does allow such a distinction and thus imparts a kind of molecular cytology to the budding yeast centromere. We note that Saitoh et al. (1997) have recently used a similar technique to demonstrate association of the Mis6 protein with DN A sequences found in the central region of Schizosaccharomyces pombe centromeres. However, in this case, as in many previous applications of in vivo cross-linking (Braunstein et al. 1993; Orlando and Paro 1993; Hecht et al. 1996), the interactions being mapped pertain to repetitive chromatin proteins that bind over many kilobases of a chromosome. Here we describe its successful application to a highly specialized multiprotein complex that assembles on a 120-bp CEN DNA sequence representing $\varangle 0.002 \%$ of the genome. Although the stoichiometry of Mif2p or $\mathrm{N}$ dc10p in the centromere is currently unknown, Cbf1p is thought to bind as a homodimer at CDEl (M ellor et al. 1990; Hegemann and Fleig 1993; Hyman and Sorger 1995). Thus, our ability to detect the presence of C bf1p underscores the potential sensitivity of this assay in the analysis of specific protein-DNA complexes. The continued application of this methodology in combination with various cis- and trans-acting centromere mutations should reveal many aspects of budding yeast centromere structure and function. Furthermore, a similar strategy could provide equally great insight into the in vivo assembly, structure, and function of other protein-DNA complexes such as promoters, enhancers, and origins of replication.

\section{Materials and methods}

Strains

A list of strains used in this study is given in Table 1.

High copy and HA-tagged alleles of MIF2 and CBF1

All DNA and bacterial manipulations were by standard protocols (Sambrook et al. 1989). Y east growth media and protocols are described in Rose et al. (1990). Plasmid pPM 44 contains a 2.6-kb MIF2 genomic Pstl fragment (cloned as a HindlII-Sacl fragment from plasmid pPM 3; M eluh and Koshland 1995) on the $2 \mu$-based URA3-containing vector pRS202. A closely related vector, pRS426, is described in Christianson et al. (1992). A centromere-based plasmid bearing MIF2-HA (pPM 102) was derived from plasmid pPM 4 (M eluh and Koshland 1995) by insertion of a 132-bp fragment encoding three copies of the HA epitope after codon 365 of the predicted MIF2 open reading frame. Haploid mif2::HIS3 strains bearing either plasmid pPM 4 or pPM 102 were obtained by transformation and subsequent dissection of heterozygous mif2::HIS3/+diploid strain 6730. A $2 \mu-$ based plasmid bearing CBF1-HA (pPM 81) was derived from pPM 35 (Meluh and Koshland 1995) by insertion of a 117-bp fragment encoding three copies of the HA epitope after codon 9 of the predicted CBFI open reading frame. Haploid CBF1-HA strain PM 1114 was derived from cbf1::URA3 (M et-) strain

Table 1. Strains used in these experiments

\begin{tabular}{lll}
\hline Strain & \multicolumn{1}{c}{ Genotype } & \multicolumn{1}{c}{ Source } \\
\hline 5371-10-2 & MATa ura3 & Brown et al. (1993) \\
6730 & MATa/MAT $\alpha$ ura3/ura3 leu2/+his3/his3 met2/+sap3/+mif2::HIS3/+ & Brown et al. (1993) \\
PM 1202-7B & MAT $\alpha$ ura3 his3 mif2::HIS3 [pPM 4; CEN-MIF2] & this study \\
PM 1203-1C & MAT $\alpha$ ura3 his3 mif2::HIS3 [pPM 102; CEN-MIF2-HA] & this study \\
BP5050 & MATa/MAT $\alpha$ leu2/+ade2/+ade3/+his7/his7 HOM3/+can1/can1 & Guacci et al. (1997) \\
& Sap3/sap3 CYC2/+gal1/gal1 & \\
MS10 & MATa ura3-52 leu2-3,112 ade2-101 & Mark Rose (Princeton University, NJ) \\
PM5371-101 & MATa ura3 cbf1::URA3 & M eluh and Koshland (1995) \\
PM 1114 & MATa ura3 CBF1-HA & this study \\
\hline
\end{tabular}


PM 5371-101 by one-step gene replacement with the 2.2-kb CBF1-HA fragment from pPM 81 and selecting for $\mathrm{M} \mathrm{et}^{+}$transformants.

\section{Generation of Mif2 antisera and immunological techniques}

Two anti-Mif2p rabbit antisera (C223 and C224) were raised against a bacterially expressed and $\mathrm{Ni}^{2+}$ affinity-purified (ProBond Resin; Invitrogen, Carlsbad, CA) 6-His-tagged fusion protein containing the carboxy-terminal 186 residues of Mif2p. Anti-Mif2p antiserum C224 was affinity purified against the 6-His-Mif2 fusion protein bound to Immobilon-P PVDF membrane (Millipore Corp., Bedford, MA; Harlow and Lane 1988). For Western blot analysis, yeast whole cell extracts were prepared by mechanically breaking cells in buffer containing $1 \%$ SDS, $100 \mathrm{~mm} \mathrm{NaCl}, 5 \mathrm{~mm}$ EDTA, $50 \mathrm{~mm}$ Tris- $\mathrm{HCl}$ at pH 7.4, and $1 \mathrm{~mm}$ PMSF. Lysates were mixed with sample buffer, heated briefly at $100^{\circ} \mathrm{C}$, and clarified. Proteins were resolved by SDSPAGE $(7.5 \%)$, transferred to nitrocellulose, and probed with Mif2p antiserum (C223; 1:2000 dilution). Proteins bound by anti-M if2p were detected using a goat anti-rabbit horseradish peroxidase-conjugated secondary antibody (Bio-Rad Laboratories, Hercules, CA) and Renaissance chemiluminescence reagent (DuPont NEN, Boston, MA). Indirect immunofluorescence was performed as described (Rose et al. 1990) except that cells were fixed for $\leqslant 1 \mathrm{hr}$, as detection of Mif2p expressed at wild-type levels was dependent on shorter fixation. Mif2p was visualized using affinity-purified anti-M if2p and a Cy3-conjugated goat anti-rabbit secondary antibody (Jackson ImmunoResearch Laboratories, Inc., West Grove, PA). Microtubules were visualized using the rat monoclonal antibody Y OL1/34 directed against yeast $\alpha$-tubulin (Serotec, Indianapolis, IN) and a FITCconjugated goat anti-rat secondary antibody. Total DNA was visualized using DAPI. Images were taken on a Zeiss Axioskop microscope using a Micromax cooled CCD camera (Princeton Instruments, Inc., Princeton, NJ) and IPLab Spectrum software (Scanalytics Corp., Vienna, VA).

\section{Segregation-incompetent derivatives of CEN 3}

The cen3-BCT2-integrating plasmid pPM 147 was created by inserting a $0.58-\mathrm{kb}$ Sall DNA fragment containing the cen3BCT 2 allele (211 bp) into the yeast-integrating plasmid pRS306 (URA3; Sikorski and Hieter 1989). The cen3-BCT2 fragment, originally derived from pBCT2 (M cGrew et al. 1986), also contains the HindlII-BamHI region of pBR322 (346 bp) 5' to CDEI. To create plasmids PPM 148 and pPM 149, which contain wildtype CEN3-CDEI+HI and CEN3-CDEIII DNA, respectively, a 0.32-kb BamHI DNA fragment, corresponding to a genomic CEN3-containing Alul fragment to which BamHI linkers had been added, was digested with Sspl. The resultant 0.12-kb Bam$\mathrm{HI}-\mathrm{Sspl}$ fragment containing CEN3-CDEI+H and the $0.2-\mathrm{kb}$ Sspl-BamHI fragment containing CEN3-CDEIII plus 3'-flanking sequence were then individually subcloned into pRS306. Plasmids pRS306, pPM 147, pPM 148, and pPM 149 were each stably integrated at the URA3 locus of wild-type yeast strain MS10 and CBF1-HA strain PM 1114 by a standard transformation protocol.

In vivo cross-linking and chromatin immunoprecipitation

Yeast strains were grown in YPD to an $O D_{600}$ of 1.2-1.5, then treated in situ with $1 \%$ formal dehyde. Fixation time varied. Cross-linked chromatin solutions suitable for immunoprecipation were prepared as described by Braunstein et al . (1993). Fixed cells were harvested, washed, and converted to spheroplasts us- ing oxalyticase. Spheroplasts were washed, resuspended in lysis buffer (1\% SDS, $10 \mathrm{~mm}$ EDTA, $50 \mathrm{~mm}$ Tris at pH 8.1), supplemented with protease inhibitors ( $1 \mathrm{mM}$ PM SF, $0.6 \mu \mathrm{g} / \mathrm{ml}$ of leupeptin, $0.8 \mu \mathrm{g} / \mathrm{ml}$ of pepstatin A), and sonicated to fragment chromosomal DNA to an average size of 300-1000 bp. Sonicated material was diluted into immunoprecipitation buffer (final concentration, $0.1 \%$ SDS; $1 \%$ Triton X-100; $150 \mathrm{~mm} \mathrm{NaCl}$; $2 \mathrm{~mm}$ EDTA; $20 \mathrm{~mm}$ Tris at $\mathrm{pH} 8.1$ ) supplemented with protease inhibitors. Aliquots of the resultant chromatin solution corresponding to $\sim 18 \mathrm{OD}_{600}$ cell equivalents were incubated with antibody overnight at $4^{\circ} \mathrm{C}$. Crude anti-Mif2p rabbit antisera were used at a 1:250 or 1:500 dilution. Affinity-purified antiMif2p antibody was used at a 1:50 dilution. In some cases, recombinant 6-His-Mif2 antigen was included in the immunoprecipitation at a concentration of $\leqslant 6.7 \mu \mathrm{g} / \mathrm{ml}$. Purified antiHA monoclonal antibody 12CA5 (BAbCO, Richmond, CA) was used at $4 \mu \mathrm{g} / \mathrm{ml}$ final concentration. The anti-N dc10p antibody, provided by Anthony Hyman (European Molecular Biology Laboratory, Heidel berg, Germany), was raised and affinity purified against the amino-terminal 444 amino acids of $\mathrm{Ndc10p}$. Following addition of sonicated $\lambda$ DNA $(2 \mu \mathrm{g})$, immune complexes were harvested by incubation with protein A-Sepharose CL-4B beads (Pharmacia Biotech, U ppsala, Sweden) for 1-2 hr. Beads were sequentially washed as described by Braunstein et al. (1993), being transferred to a fresh tube prior to the final TE wash (10 mM Tris at pH 8.0, 1 mm EDTA). Immunoprecipitated material was eluted from the beads with $1 \%$ SDS, $0.1 \mathrm{~m}$ $\mathrm{Na}_{2} \mathrm{CO}_{3}$, heated at $65^{\circ} \mathrm{C}$ for $4-5 \mathrm{hr}$ to reverse formal dehyde cross-links, and ethanol precipitated. Aliquots of total chromatin solution were similarly heat treated and preci pitated. Recovered material was treated with proteinase K (Boehringer M annheim, Germany), extracted with organic solvents, and ethanol precipitated.

\section{Analysis of coimmunoprecipitated DNA}

Resultant total input DNA and coimmunoprecipitated DNA samples were analyzed by sl ot bl ot or Southern hybridization, or by PCR. For sl ot blot analysis, DNA samples were diluted in $6 \times$ SSC, denatured by heating at $100^{\circ} \mathrm{C}$ for $10 \mathrm{~min}$, and applied to Nytran membrane filters (Schleicher \& Schuell; Keene, NH). For Southern analysis, DNA samples were cut with Alul, treated with RN ase, resolved on $2.5 \%$ agarose gels, and transferred to GeneScreen Plus (NEN Research Products; Boston, MA). $\left[\alpha^{-}{ }^{32} P\right] d A$ TP-Labeled hybridization probes were prepared by random hexamer priming using the following templates: a 244-bp CEN3-containing PCR fragment (Sau3A/Primer 1 product; see Fig. 3A); a 345-bp CEN 16-containing PCR fragment (see bel ow); a 660-bp Bglll fragment from the coding region of TU B2; and sonicated total yeast DNA. Blots were hybridized and washed as described by Church and Gilbert (1984). Hybridized blots were digitally imaged and quantitated using the storage Phospor technology of the Storm 860 imaging system and ImageQuant software (M olecular Dynamics, Inc.; Sunnyvale, CA). PCR reactions ( 24 cycles) used $1 / 50$ of the immunoprecipitates and $1 / 500$ of the total material input and serial dilutions thereof. PCR products (one-third reaction) were separated on $8 \%$ polyacrylamide gels and visualized with ethidium bromide. The region encompassing CEN3 (bp 113925-114168 of chromosome III) was amplified with the Sau3A primer (5'-GATCAGCGCCAAACAATATGG-3') and Primer 1 (5'-AACTTCCACCAGTAAACGTTTC-3'), as indicated in Figure $3 A$. The cen3-BCT2 mutation was amplified with Primer 2 (5'-CACTATCGACTACGCGATCA-3'; 5'-to pBR322 BamHI site) and the T3 primer (5'-AATTAACCCTCACTAAAGGG-3'). Other segregation incompetent CEN 3 derivatives and the pRS306 polylinker 
were amplified with the T3 and T7 (5'-TAATACGACTCACTATAGGG-3') primers, which flank the pRS306 polylinker. To test noncentromeric loci on chromosome III, primer pairs were designed that correspond to part of the LEU 2 coding region (bps 91019-91267; 23 kb to the left of CEN3); an AT-rich intergenic region near PGK1 (bp 138557-138845; $\sim 24.5-\mathrm{kb}$ to the right of CEN 3); and an AT-rich intergenic region near HMRa (bp 291213-291527; 177 kb to the right of CEN 3). Primers specific for CEN 16 (bp 555845-556189 on chromosome XVI) and CEN 1 (bp 151379-151681 on chromosome I) were also used. Details regarding primers for amplification of fragments adjacent to CEN 3 and CEN 16 are available on request.

\section{Acknowledgments}

We gratefully thank Anthony Hyman for generously providing anti-N dc10p antibody, Alejandro Roth for assistance in the construction of the epitope-tagged MIF2-HA strain, and members of the Koshland laboratory for critical reading of the manuscript. This work was supported by grant GM 41718-07 from the $\mathrm{N}$ ational Institutes of Heal th to D.K.

The publication costs of this article were defrayed in part by payment of page charges. This article must therefore be hereby marked "advertisement" in accordance with 18 USC section 1734 solely to indicate this fact.

\section{Note added in proof}

We note that Tomoyuki et al. (Cell 90: 649-660) and A paricio et al. (Cell 91: 59-69) have recently applied in vivo cross-linking to the analysis of yeast origins of replication. Also, Starr et al. (). Cell Biol. 138: 1289-1301) have recently identifed homologs of the Drosophila ZW10 centromere protein in diverse plant and animal species, further supporting the idea of structural conseration within centromeres.

\section{References}

Baker, R.E. and D.C. Masison. 1990. Isolation of the gene encoding the Saccharomyces cerevisiae centromere-binding protein CP1. Mol. Cell. Biol. 16: 2458-2467.

Baker, R.E., M. Fitzgerald-Hayes, and T.C. O'Brien. 1989. Purification of the yeast centromere binding protein $\mathrm{CP} 1$ and a mutational analysis of its binding site. J. Biol. Chem. 264: 10843-10850.

Basrai, M.A., J. Kingsbury, D. Koshland, F. Spencer, and P. Hieter. 1996. Faithful chromosome transmission requires Spt4p, a putative regulator of chromatin structure in Saccharomyces cerevisiae. Mol. Cell. Biol. 16: 2838-2847.

Bloom, K.S. and J. Carbon. 1982. Yeast centromere DN A is in a unique and highly ordered structure in chromosomes and small circular minichromosomes. Cell 29: 305-317.

Braunstein, M., A.B. Rose, S.G. Holmes, C.D. Allis, and J.R. Broach. 1993. Transcriptional silencing in yeast is associated with reduced nucleosome acetylation. Genes \& Dev. 7: 592604.

Brinkley, B.R., I. Ouspenski, and R.P. Zinkowski. 1992. Structure and molecular organization of the centromere-kinetochore complex. Trends Cell Biol. 2: 15-21.

Brown, M.T. 1995. Sequence similarities between the yeast chromosome segregation protein Mif2 and the mammalian centromere protein CEN P-C. Gene 160: 111-116.

Brown, M.T., L. Goetsch, and L.H. Hartwell. 1993. MIF2 is required for mitotic spindle integrity during anaphase spindle elongation in Saccharomyces cerevisiae. J. Cell Biol.
123: 387-403.

Cai, M . and R.W. Davis. 1990. Yeast centromere binding protein CBF1, of the helix-loop-helix protein family, is required for chromosome stability and methionine prototrophy. Cell 61: 437-446.

Christianson, T.W., R.S. Sikorski, M. Dante, J.H. Shero, and P. Hieter. 1992. Multifunctional yeast high-copy-number shuttle vectors. Gene 110: 119-122.

Church, G.M. and W. Gilbert. 1984. Genomic sequencing. Proc. Natl. Acad. Sci. 81: 1991-1995.

Connelly, C. and P. Hieter. 1996. Budding yeast SKP1 encodes an evolutionarily conserved kinetochore protein required for cell cycle progression. Cell 86: 275-285.

Cooke, C.A., R.L. Bernat, and W.C. Earnshaw. 1990. CEN P-B: A major human centromere protein located beneath the kinetochore. J. Cell Biol. 110: 1475-1488.

Dedon, P.C., J.A. Soults, C.D. Allis, and M.A. Gorovsky. 1991. A simplified formaldehyde fixation and immunoprecipitation technique for studying protein-DN A interactions. Anal. Biochem. 197: 83-90.

Doheny, K., P. Sorger, A. Hyman, S. Tugendreich, F. Spencer, and P. Hieter. 1993. Identification of essential componenets of the S. cerevisiae kinetochore. Cell 73: 761-774.

du Sart, D., M.R. Cancilla, E. Earle, J.I. Mao, R. Saffery, K.M. Tainton, P. Kalitsis, J. Martyn, A.E. Barry, and K.H. Choo. 1997. A functional neo-centromere formed through activation of a latent human centromere and consisting of nonal pha-satellite DN A. N ature Genet. 16: 144-153.

Earnshaw, W.C., H. Ratrie, and G. Stetten. 1989. Visualization of centromere proteins CENP-B and CEN P-C on a stable dicentric chromosome in cytological spreads. Chromosoma 98: 1-12.

Fitzgeral d-Hayes, M., L. Clarke, and J. Carbon. 1982. N ucleotide sequence comparisons and functional analysis of yeast centromere DN As. Cell 29: 235-244.

Goh, P.Y. and J. Kilmartin. 1993. NDC10: A gene involved in chromosome segregation in S. cerevisiae. J. Cell Biol. 121: 503-512.

Gorbsky, G.J. 1995. Kinetochores, microtubules and the metaphase checkpoint. Trends Cell Biol. 5: 143-148.

Grady, D.L., R.L. Ratliff, D.L. Robinson, E.C. McCanlies, J. Meyne, and R.K. Moyzis. 1992. Highly conserved repetitive DNA sequences are present at human centromeres. Proc. Natl. Acad. Sci. 89: 1695-1699.

Guacci, V., E. Hogan, and D. Koshland. 1997. Centromere position in budding yeast: Evidence for anaphase A. Mol. Biol. Cell 8: 957-972.

Harlow, E. and D. Lane. 1988. Antibodies: A laboratory manual. Cold Spring Harbor Laboratory, Cold Spring Harbor, NY.

Hecht, A., S. Strahl-Bolsinger, and M. Grunstein. 1996. Spreading of transcriptional repressor SIR3 from telomeric heterochromatin. Nature 383: 92-96.

Hegemann, J.H. and U.N. Fleig. 1993. The centromere of budding yeast. BioEssays 15: 451-460.

Hyman, A.A. and P.K. Sorger. 1995. Structure and function of kinetochores in budding yeast. Annu. Rev. Cell Dev. Biol. 11: 471-495.

Jiang, W., J. Lechner, and J. Carbon. 1993. Isolation and characterization of a gene (CBF2) specifying a protein component of the budding yeast kinetochore. J. Cell Biol. 121: 513-519.

Kingsbury, J. and D. Koshland. 1991. Centromere-dependent binding of yeast minichromosomes to microtubules in vitro. Cell 66: 483-495.

Kuras, L., R. Barbey, and D. Thomas. 1997. Assembly of a bZIPbHLH transcription activation complex: Formation of the 
yeast $\mathrm{Cbf1-M}$ et4-M et28 complex is regulated through $\mathrm{M}$ et28 stimulation of Cbf1 DNA binding. EMBO J. 16: 2441-2451.

Lechner, J. 1994. A zinc finger protein, essential for chromosome segregation, constitutes a putative DNA binding subunit of the Saccharomyces cerevisiae kinetochore complex, Cbf3. EMBO J. 13: 5203-5211.

Lechner, J. and J. Carbon. 1991. A 240 kD multisubunit protein complex, CBF3, is a major component of the budding yeast centromere. Cell 64: 717-725.

M asumoto, H., H. Masukata, Y. M uro, N. N ozaki, and T. Okazaki. 1989. A human centromere antigen (CEN P-B) interacts with a short specific sequence in alphoid DNA, a human centromeric satellite. J. Cell Biol. 109: 1963-1973.

McGrew, J., B. Diehl, and M. Fitzgerald-Hayes. 1986. Single base-pair mutations in centromere element III cause aberrant chromosome segregation in Saccharomyces cerevisiae. Mol. Cell. Biol. 6: 530-538.

Mellor, J., W. Jiang, M. Funk, J. Rathjan, C.A. Barnes, T. Hinz, J.H. Hegemann, and P. Philippsen. 1990. CPF1, a yeast protein which functions in centromeres and promoters. EMBO J. 8: 4017-4026.

Meluh, P.B. and D. Koshland. 1995. Evidence that the MIF2 gene of Saccharomyces cerevisiae encodes a centromere protein with homology to the mammalian centromere protein CEN P-C. Mol. Biol. Cell. 6: 793-807.

$\mathrm{Ng}, \mathrm{R}$. and J. Carbon. 1987. Mutational and in vitro proteinbinding studies on centromere DNA from Saccharomyces cerevisiae. Mol. Cell. Biol. 7: 4522-4534.

Orlando, V. and R. Paro. 1993. Mapping Polycomb-repressed domains in the bithorax complex using in vivo formal dehyde cross-linked chromatin. Cell 75: 1187-1198.

Orlando, V., H. Strutt, and R. Paro. 1997. A nalysis of chromatin structure by in vivo formaldehyde cross-linking. Methods 11: 205-214.

Pangilinan, F. and F. Spencer. 1996. Abnormal kinetochore structure activates the spindle assembly checkpoint in budding yeast. Mol. Biol. Cell 7: 1195-1208.

Pluta, A., A. Mackay, A. Ainsztein, I. Goldberg, and W. Earnshaw. 1995. The centromere: Hub of chromosomal activities. Science 270: 1591-1594.

Rose, M.D., F. Winston, and P. Hieter. 1990. Methods in yeast genetics: A laboratory course manual. Cold Spring Harbor Laboratory Press, Cold Spring Harbor, NY.

Rudner, A.D. and A.W. Murray. 1996. The spindle assembly checkpoint. Curr. Opin. Cell Biol. 8: 773-780.

Saitoh, H., J. Tomkiel, C.A. Cooke, H. Ratrie, M. Maurer, N.F. Rothfield, and W.C. Earnshaw. 1992. CEN P-C, an autoantigen in scleroderma, is a component of the human inner $\mathrm{ki}$ netochore plate. Cell 70: 115-125.

Saitoh, S., Takahashi, K., and M. Y anagida. 1997. M is6, a fission yeast inner centromere protein, acts during $\mathrm{G} 1 / \mathrm{S}$ and forms specialized chromatin required for equal segregation. Cell 90: 131-143.

Sambrook, J., E.F. Fritsch, and T. Maniatis. 1989. Molecular cloning: A laboratory manual, 2nd ed. Cold Spring Harbor Laboratory Press, Cold Spring Harbor, NY.

Saunders, M., M. Fitzgerald-Hayes, and K. Bloom. 1988. Chromatin structure of altered yeast centromeres. Proc. Natl. Acad. Sci. 85: 175-179.

Saunders, M.J., E. Yeh, M. Grunstein, and K. Bloom. 1990. $\mathrm{N}$ ucl eosome depletion al ters the chromatin structure of Saccharomyces cerevisiae centromeres. Mol. Cell. Biol. 10: $5721-5727$.

Schulman, I.G. and K. Bloom. 1993. Genetic dissection of centromere function. Mol. Cell. Biol. 13: 3156-3166.

Sikorski, R.S. and P. Hieter. 1989. A system of shuttle vectors and yeast host strains designed for efficient manipulation of DN A in Saccharomyces cerevisiae. Genetics 122: 19-27.

Smith, M.M., P. Yang, S.M. Soledad, P.W. Boone, A.T. Goldstein, and P.C. Megee. 1996. A novel histone H4 mutant defective in nuclear division and mitotic chromosome transmission. Mol. Cell. Biol. 16: 1017-1026.

Sorger, P.K., F.F. Severin, and A.A. Hyman. 1994. Factors required for the binding of reassembled yeast kinetochores to microtubules in vitro. J. Cell Biol. 127: 995-1008.

Sorger, P.K., K.F. Doheny, P. Hieter, K.M. Kopski, T.C. Huffaker, and A.A. Hyman. 1995. Two genes required for the binding of an essential Saccharomyces cerevisiae kinetochore complex to DNA. Proc. Natl. Acad. Sci. 92: 1202612030.

Stemmann, O. and J. Lechner. 1996. The Saccharomyces cerevisiae kinetochore contains a cyclin-CDK complexing homologue, as identified by in vitro reconstitution. EMBO J. 15: 3611-3620.

Stoler, S., K.C. Keith, K.E. Curnick, and M. Fitzgerald-Hayes. 1995. A mutation in CSE4, an essential gene encoding a novel chromatin-associated protein in yeast, causes chromosome nondisjunction and cell cycle arrest at mitosis. Genes \& Dev. 9: 573-586.

Strunnikov, A.V., J. Kingsbury, and D. Koshland. 1995. CEP3 encodes a centromere protein of Saccharomyces cerevisiae. J. Cell Biol. 128: 749-760.

Sullivan, B.A. and S. Schwartz. 1995. Identification of centromeric antigens in dicentric Robertsonian translocations: CEN P-C and CENP-E are necessary components of functional centromeres. Hum. Mol. Genet. 4: 2189-2197.

Sullivan, K.F., M. Hechenberger, and K. Masri. 1994. Human CEN P-A contains a histone $\mathrm{H} 3$ related histone fold domain that is required for targeting to the centromere. J. Cell Biol. 127: 581-592.

Tomkiel, J., C.A. Cooke, H. Saitoh, R.L. Bernat, and W.C. Earnshaw. 1994. CEN P-C is required for maintaining proper kinetochore size and for a timely transition to anaphase. J. Cell Biol. 125: 531-545.

Tyler-Smith, C. and H.F. Willard. 1993. Mammalian chromosome structure. Curr. O pin. Genet. Dev. 3: 390-397.

Wilmen, A., H. Pick, R.K. Niedenthal, M. Sen-Gupta, and J.H. Hegemann. 1994. The yeast centromere CDEl/Cpf1 complex: Differences between in vitro binding and in vivo function. Nucleic Acids Res. 22: 2791-2800.

Winey, M., C.L. Mamay, E.T. O'T oole, D.N. Mastronarde, T.H. Giddings, K.L. McDonald, and J.R. Mclntosh. 1995. Threedimensional ultrastructural analysis of the Saccharomyces cerevisiae mitotic spindle. J. Cell Biol. 129: 1601-1615.

Zinkowski, R.P., J. Meyne, and B.R. Brinkley. 1991. The centromere-kinetochore complex: a repeat subunit model. J. Cell Biol. 113: 1091-1110. 


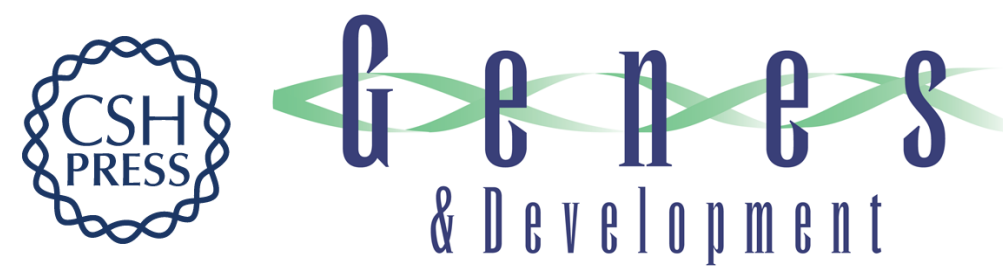

\section{Budding yeast centromere composition and assembly as revealed by in vivo cross-linking}

Pamela B. Meluh and Douglas Koshland

Genes Dev. 1997, 11:

Access the most recent version at doi:10.1101/gad.11.24.3401

References This article cites 58 articles, 30 of which can be accessed free at: http://genesdev.cshlp.org/content/11/24/3401.full.html\#ref-list-1

License

Email Alerting

Receive free email alerts when new articles cite this article - sign up in the box at the top Service right corner of the article or click here.

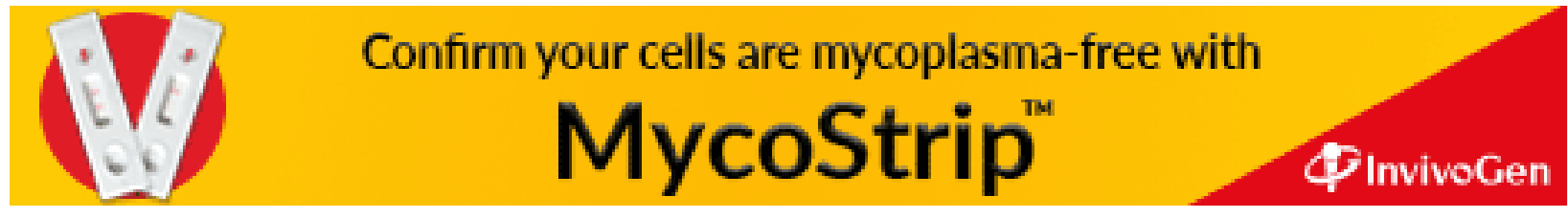

